Report No. BMI-1408

UC-25 Metallurgy and Ceramics

(TID-4500, 15th Ed.)

Contract No. W-7405-eng-92

\title{
A METHOD OF CORRELATING IRRADIATION EFFECTS IN DISPERSION FUELS
}

by

Donald L. Keller

Lewis $E$. Hulbert

Bruce $W$. Dunnington

Janua ry 20, 1960

BATTELLE MEMORIAL INS TITUTE

$505 \mathrm{King}$ Avenue

Columbus 1 , Ohio 


\section{DISCLAIMER}

This report was prepared as an account of work sponsored by an agency of the United States Government. Neither the United States Government nor any agency Thereof, nor any of their employees, makes any warranty, express or implied, or assumes any legal liability or responsibility for the accuracy, completeness, or usefulness of any information, apparatus, product, or process disclosed, or represents that its use would not infringe privately owned rights. Reference herein to any specific commercial product, process, or service by trade name, trademark, manufacturer, or otherwise does not necessarily constitute or imply its endorsement, recommendation, or favoring by the United States Government or any agency thereof. The views and opinions of authors expressed herein do not necessarily state or reflect those of the United States Government or any agency thereof. 


\section{DISCLAIMER}

Portions of this document may be illegible in electronic image products. Images are produced from the best available original document. 
ABSTRACT

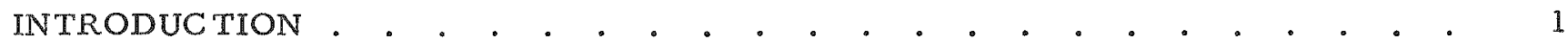

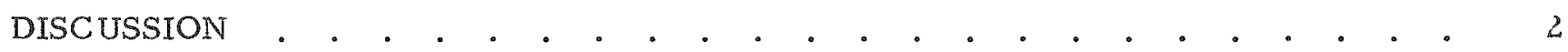

The Model of Creep Failure . . . . . . . . . . . . . . . . 2

The Model of Failure by Short-Term Stress Peaks. . . . . . . . . 4

Application of the Failure Models . . . . . . . . . . . . . . 5

Presentation and Analysis of the Experimental Results . . . . . . . 10

CONCLUSIONS. . . . . . . . . . . . . . . . . . . . . . . . . . 14

REFERENCES 。 . . . . . . . . . . . . . . . . . . . . . . 15 


\title{
A METHOD OF CORRELATING IRRADIATION EFFECTS IN DISPERSION FUELS
}

Donald L. Keller, Lewis E. Hulbert, and Bruce W. Dunnington

\begin{abstract}
No satisfactory method of predicting the life of dispersion fuels is in present use because the complexity of the factors relating to the structure of the fuel material and to the fluctuations in irradiation conditions males meaningful correlation and interpretation of experimental data extremely difficult. In the present study, a method was proposed in which the effects of irradiation conditions are considered independently of material variables. Two simple failure models were devised (failure by creep and by short-term yield), and criteria which permit estimates of the relative severity of tests made under different test conditions but on identical specimens uere developed.
\end{abstract}

Numerical application of the procedures for 18-8 stainless steel -25 and $-30 \mathrm{w} / \mathrm{O} \mathrm{IO}_{2}$ specimens was attempted. No positive verification of the shortterm stress model u'as obtained, but the creep model yielded the approximate failure limits for both specimen compositions.

\section{INTRODUC TION}

The successful use of dispersion fuels in the Army Package Power Reactor $(1,2)$ and other compact systems has stimulated interest in fuels of this type. The te rm "dispersion fuel" as used in this report will be taken to mean a cermet material in which particles of en riched uranium oxide ceramic are dispersed in a metallic matrix. Nonmetallic matrix materials will not be considered here.

The advantage of the dispersion concept is that fuels with widely differing properties may be obtained by mixing different metals with $\mathrm{UO}_{2}$ or other uranium compounds and by varying the composition and geometrical structure of the mixtures. Although significant advances have been made in the technology and fabrication of dispersion fuel elements (3), service time of most dispersion fuels is limited by the necessity of containing the fission gas produced by the irradiation process. A fraction of the gas products generated by fission of uranium in the oxide will reach the surface of the oxide particles and collect at the metal-oxide interfaces. As the irradiation is continued, more gas escapes to the interface, and the resulting pressure eventually becomes sufficient to disrupt the metal matrix and cause the fuel element to swell and to rupture. In present reactor designs, swelling of a fuel element is undesirable. There is currently no method available for predicting the conditions at which a given fuel element will swell, and, as a safety measure, dispersion fuel elements must be used in a reactor for only a fraction of their useful life. It would therefore be desirable to be able to predict the conditions at which a given fuel element will swell.

The factors that affect the life of a dispersion fuel element are the material properties of the matrix metal, the structure of the specimen, and the irradiation conditions, including the duration of irradiation, the specimen temperature, and the burnup of the fuel. Many experiments have been made to determine the effects of these factors on fuel-element life. However, it has been difficult to interpret these test results in a meaningful way for two reasons:

(1) References at end. 
(1) The structure of a dispersion fuel is so complex that the development of a satisfactory failure theory based on a detailed mathematical model of the structure has been prohibitively difficult.

(2) The test conditions may fluctuate during an irradiation experiment, making correlations with specimen temperature difficult.

A method is proposed in this report to uncouple the effects of the variation of the test parameters from the material propexties. Thus the relative effects of changing the test conditions are to be considered independently of the effects of other variables. Two failure models are proposed (failure by creep and by short-term yield), and criteria are developed from these models which permit estimates of the relative severity of tests made under different test conditions but on identical specimens. If a set of tests yields both failed and unfailed specimens, the proposed analysis may be used to make estimates of the various combinations of the test parameters that will produce a failed specimen of the given material.

Numerical application of the procedures is presented for $18-8$ stainless steel- $\mathrm{UO}_{2}$ cermets. Two sets of experiments were evaluated using the proposed methods. The results indicate that the procedures may prove useful in interpreting experimental results.

\section{DISCUSSION}

The Model of Creep Failure

If a full specimen is irradiated for extended periods at uniform elevated temperatures, it will undergo creep deformation. Although the stress distribution in such a specimen is complex, it will be assumed that the dependence of the over-all creep rate on stress and temperature will be of the same form as for uniaxial tension. For the present analysis, this dependence can be expressed with sufficient generality by the empirical relation:

$$
\dot{\epsilon}=\mathrm{A} \sigma \mathrm{n}_{\mathrm{e}}-\mathrm{Q} / \theta \text {, }
$$

where

$$
\begin{aligned}
& \dot{\epsilon} \text { is the strain rate } \frac{d \epsilon}{d t} \\
& \sigma \text { is the stress } \\
& \theta \text { is the absolute specimen temperature }
\end{aligned}
$$

$$
\text { A., } n, Q \text { are constants. }
$$

No attempt will be made here to determine the spatial stress distribution in the cermet. The over-all stress level priox to specimen failure will be assumed proportional to the gas pressure in the voids. Since the major gaseous fission products are noble gases, the ideal gas law is a good approximation: 
$\sigma \propto \mathbb{P}=K M \theta / V$

where

$P$ is the pressure

$K$ is a constant

$M$ is the amount of gas in the pores

$V$ is the volume of the pore space.

It will be assumed that a constant fraction of the generated fission products is released to the pore spaces so that the amount of gas in the pores is proportional to the burnup. The mechanism of release of fission gas to the pore space and its dependence on time, temperature, and burnup is not known. It is in this area that future research will be most illuminating. In addition, the elastic strain at the elevated temperatures of the test may be neglected in comparison with the creep strain so that $V$ is effectively a function only of the creep strain $\epsilon$. We have then

$$
\sigma=\operatorname{cB} \theta / \mathrm{V}(\epsilon)
$$

where $\mathrm{c}$ is some proportionality constant and $B$ is burnup.

Substituting Equation (2) in Equation (1) and rearranging gives:

$$
\frac{\mathrm{V}^{\mathrm{n}}(\epsilon)}{\mathrm{c}^{\mathrm{n}} \mathrm{A}} \mathrm{d} \epsilon=\mathrm{B}^{\mathrm{n}} \theta^{\mathrm{n}_{\mathrm{e}}}-\mathrm{Q} / \theta \mathrm{dt}
$$

Integrating both sides gives:

$$
\frac{1}{c^{n_{A}}} \int_{0}^{\epsilon_{f}} V^{n}(\epsilon) d \epsilon=\int_{0}^{t_{f}} B^{n} n^{n_{e}}-Q / \theta d t,
$$

where $\epsilon_{f}$ and $t_{f}$ are the creep and time at the end of the experiment.

We will now define the creep parameter $\alpha(\epsilon)$ by the relation

$$
\alpha(\epsilon)=\frac{1}{c^{n_{A}}} \int_{0}^{\epsilon} V^{n}(\epsilon) d \epsilon \text {. }
$$

It is seen that $\alpha$ is a function only of $\epsilon$ and the structure of the specimen. We have then

$$
\alpha\left(\epsilon_{f}\right)=\int_{0}^{t_{f}} B^{n_{\theta} n} e^{-Q / \theta} d t
$$


If the burnup and temperature are known functions of time for an experiment, the integral on the right side of Equation (4) may be evaluated numerically. The values of $\alpha$ obtained from a number of different experiments on identical specimens may be used to compare the relative severity with respect to creep of the different tests. In particular, if the creep strain at rupture for uniaxial creep were independent of temperature and pressure, then a set of identical specimens would all be expected to fail at the same value of $a$. Although the assumption of the independence of $\epsilon_{f}$ from temperature and stress is not strictly valid, it should be possible to obtain experimental correlations between the test parameters and the value of $a$ at specimen failure.

An interesting special case of Equation (4) is obtained if the burnup rate, $b$, and the temperature are constant during the course of the experiment. Then $B=b t$ and we can write from Equation (4)

$$
\begin{aligned}
\alpha\left(\epsilon_{f}\right) & =b^{n} \theta^{n} e^{-Q / \theta} \int_{0}^{t_{f}} t^{n} d t \\
& =\frac{b^{n}}{n+1} t_{f}^{n+1} \theta^{n} e^{-Q / \theta},
\end{aligned}
$$

or

$$
\alpha\left(\epsilon_{f}\right)=\frac{1}{n+1} B_{f}^{n_{t}} \theta_{f}^{n} e^{-Q / \theta}
$$

Equation (5) shows the effect of the test duration on the failure of a specimen. If two specimens are irradiated at the same temperature to the same total burnup but at different burnup rates, the specimen irradiated at a lower burnup rate over a longer period of time will be more likely to fail than the rapidly ir radiated specimen. This time effect is frequently overlooked in the comparison of irradiation experiments.

\section{The Model of Failure by Short-Term Stress Peaks}

If the dispersion fuel specimen undergoes a sudden temperature rise during its irradiation, it is possible for the resultant stresses to cause failure by exceeding the ultimate tensile stress of the metal matrix at the given temperature. Since it is not possible to estimate the actual stress distribution in the matrix of the cermet, the failure conditions cannot be calculated directly. However, it is possible to compare the relative severity with respect to the stress conditions of different combinations of time, temperature, and burnup.

Let the relative stress $\sigma_{r}$ be defined as a quantity proportional to the ratio between actual and allowable stresses. Then the test condition producing the greatest relative stress is the most critical condition with respect to yield failure.

In this case, the metal matrix will be assumed rigid so that by Equation (2):

$$
\sigma=\stackrel{c}{B} \theta
$$


If it is now assumed that the allowable stress is proportional to the ultimate strength $\sigma_{u l t}$ of the matrix metal in uniaxial tension, then:

$$
\sigma_{\mathbf{r}}=\frac{\mathbb{K B} \theta}{\sigma_{u I t}},
$$

where $K$ is a constant.

If $\sigma_{\text {ult }}$ is a known function of temperature, then the point at which the greatest $\sigma_{r}$ is reached during any experiment can be evaluated from Equation (7). A graphical method for performing this operation will be presented in the next section.

\section{Application of the Failure Models}

The numerical application of the failure models will be illustrated for the case whe re the matrix metal is $18-8$ stainless steel.

In order to use these models, it is necessary to evaluate $n$ and $Q$ from Equation(1) and $\sigma_{\text {ult }}(\theta)$ from Equation (7).

Figure 1 presents graphically some data on the creep rates of 18-8 stainless steel. (4) The solid lines were fitted to the data by eye, subject to the restriction that $\mathrm{n}$ is independent of temperature. From these lines, $\mathrm{n}$ was found to be 4.46 and two values of $Q$ were found:

$$
\begin{aligned}
& Q_{1}=-3.11 \times 10^{4} \text { for } \theta \leq 1560 R \\
& Q_{2}=-5.43 \times 10^{4} \text { for } \theta \geq 1560 R .
\end{aligned}
$$

Substituting these values in Equation (4) and arranging the expression so that the two segments intersect at $\theta=1560 \mathrm{R}$ give the results

$$
\alpha=\int_{0}^{t_{f}}(B \theta)^{4.46} \exp \left[Q_{i}\left(\frac{1}{\theta}-\frac{1}{1560}\right)\right] d t,
$$

where $Q_{i}$ is taken to be $Q_{1}$ of Equation (8) during those times that $\theta \leq 1560 R$ and $Q_{2}$ during those times that $\theta \geq 1560 \mathrm{R}$.

Substitution of Equation (8) into Equation (5) gives for constant temperature and burnup rate:

$$
\begin{aligned}
& \alpha=\frac{1}{5.46}\left(\mathrm{~B}_{f} \theta\right)^{4.46} \mathrm{t}_{f} \exp \left[-3.11 \times 10^{4}\left(\frac{1}{\theta}-\frac{1}{1560}\right)\right], \theta \leq 1560 \mathrm{R} \\
& \alpha=\frac{1}{5.46}\left(\mathrm{~B}_{\mathrm{f}} \theta\right)^{4.46} \mathrm{t}_{f} \exp \left[-5.43 \times 10^{4}\left(\frac{1}{\theta}-\frac{1}{1560}\right)\right], \theta \geq 1560 \mathrm{R} .
\end{aligned}
$$




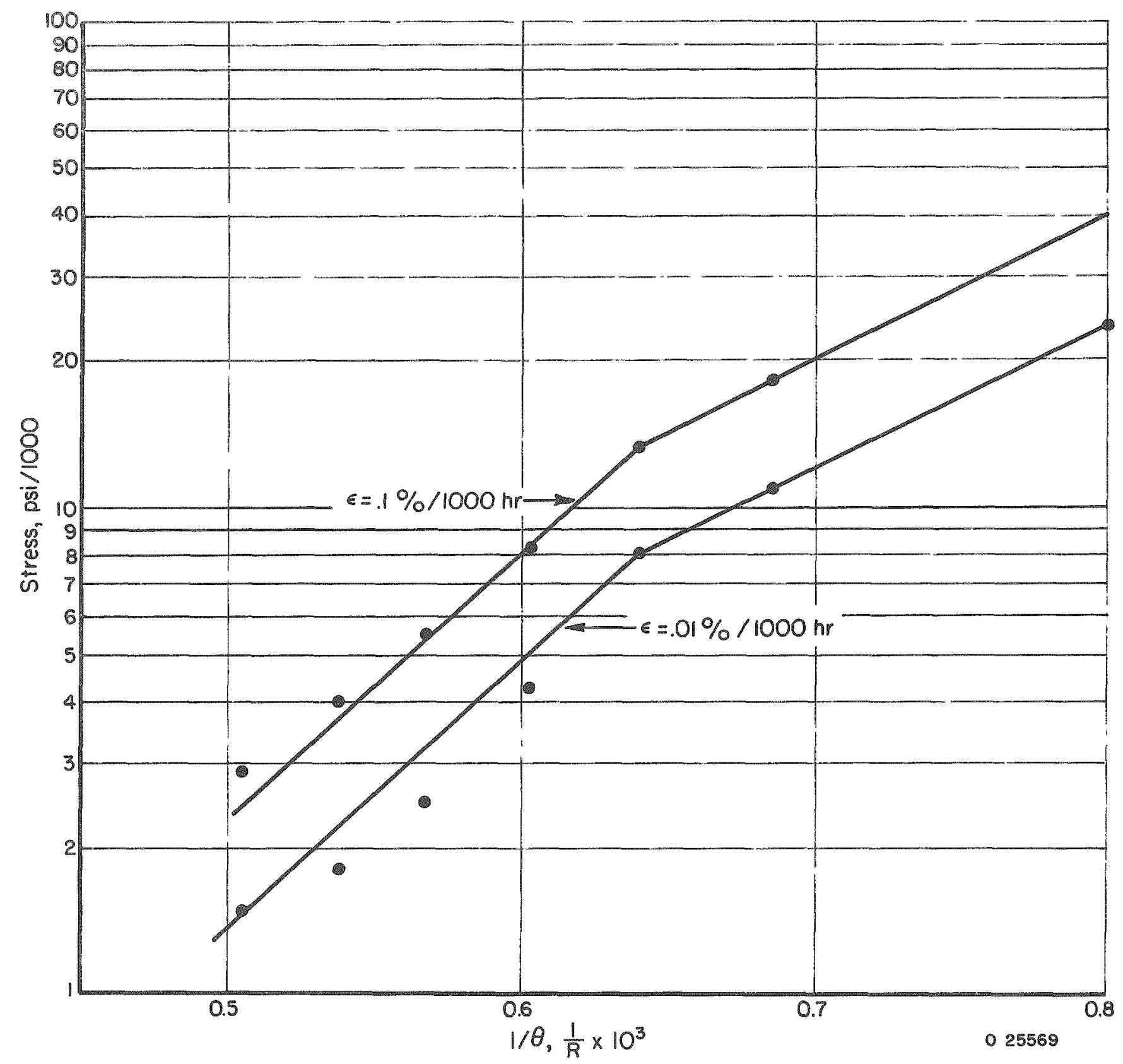

FIGURE 1. CREEP RATE DATA VERSUS TEMPERATURE AND STRESS FOR 18-8 STAINLESS STEEL 
Figure 2 is plotted from Equation (10) and shows the variation of $\alpha$ with $\theta$ for constant values of $B^{n_{t}}$. The values of $\alpha$ and $B^{n_{t}}$ are entered as the common logarithms because of their wide ranges. (To facilitate use of the graph $\theta$ is given here in F.)

To obtain a better insight into the results of an ixradiation experiment, it is desirable to be able to obtain an average temperature for the experiment. The arithmetic average of the specimen temperature has often been used:

$$
\bar{\theta}=\frac{1}{t_{f}} \int_{0}^{t_{f}} \theta d t .
$$

Figure 2 can be used to obtain a more meaningful average temperature in a manner similar to that used by Sherby and Dorn $(5)$ in creep tests. The value of $\alpha$ is first computed according to Equation (9). Then with this value of $\alpha$ and the value of $B_{f}{ }^{n_{f}} k_{k n o w n}$ for the experiment, the average temperature (which will be denoted as the "effective temperature") is read from Figure 2. This temperature is the uniform temperature at which a test would have to be performed to give the same total creep at the same final values of burnup and time as the given experiment.

The variation of $\sigma_{\text {ult }}$ with temperature for $18-8$ stainless steel is shown in Figure 3. Although the usual correlation used for these types of data is exponential, the data were correlated very well with the two straight lines shown in Figure 3 . The equations obtained from this correlation were:

$$
\begin{array}{ll}
\sigma_{\text {ult }}=96,000-29.17 \theta & \theta \leq 1560 \mathrm{R} \\
\sigma_{\text {ult }}=154,100-66.45 \theta & \theta \geq 1560 \mathrm{R}
\end{array}
$$

We now rewrite Equation (7) in the form:

$$
\frac{\sigma_{x}}{K B_{1}}=\frac{\theta B 1}{r_{u l t}}
$$

where $B_{1}=B / B_{f}$, and $\sigma_{u l t}$ is given by Equation (11). Using this equation, Figure 4 was constructed to show curves of constant $\sigma_{x} / \mathrm{KB}_{\mathrm{f}}$ for a variation in $\mathrm{B}_{1}$ and $\theta$. If temperature versus $B_{1}$ for a given experiment is plotted to the same scale, Figure 4 can be used as an overlay. The most critical stress state will then be readily apparent as that point on the burnup-temperature curve that projects above the highest curve of $\sigma_{\mathrm{r}} / \mathrm{KB}_{\mathrm{f}}$ (as in Figure $2, \theta$ is given in $F$ to facilitate using the graph). Note that, because of this method of application, no labeling of individual curves is needed in Figure 4 since the specific value of $\sigma_{x} / \mathrm{KB}_{f}$ is not of primary interest, but rather the burnup at which the most severe condition existed. The convergence of all curves to the same value of temperature at $B_{1}=0$ is a result of the fact that at that temperature the ultimate strength of the metal is zero, as shown in Figure 3.

Constructing the graph of temperature versus relative burnup $\mathrm{B}_{1}$ may be a tedious procedure. If the burnup rate is relatively constant over the duration of the experiment, an estimate of the critical stress condition of the experiment may be obtained in the following way: Assuming a constant burnup rate gives

$$
B=b t=b t_{1} t_{f}=B_{f} t_{1}
$$




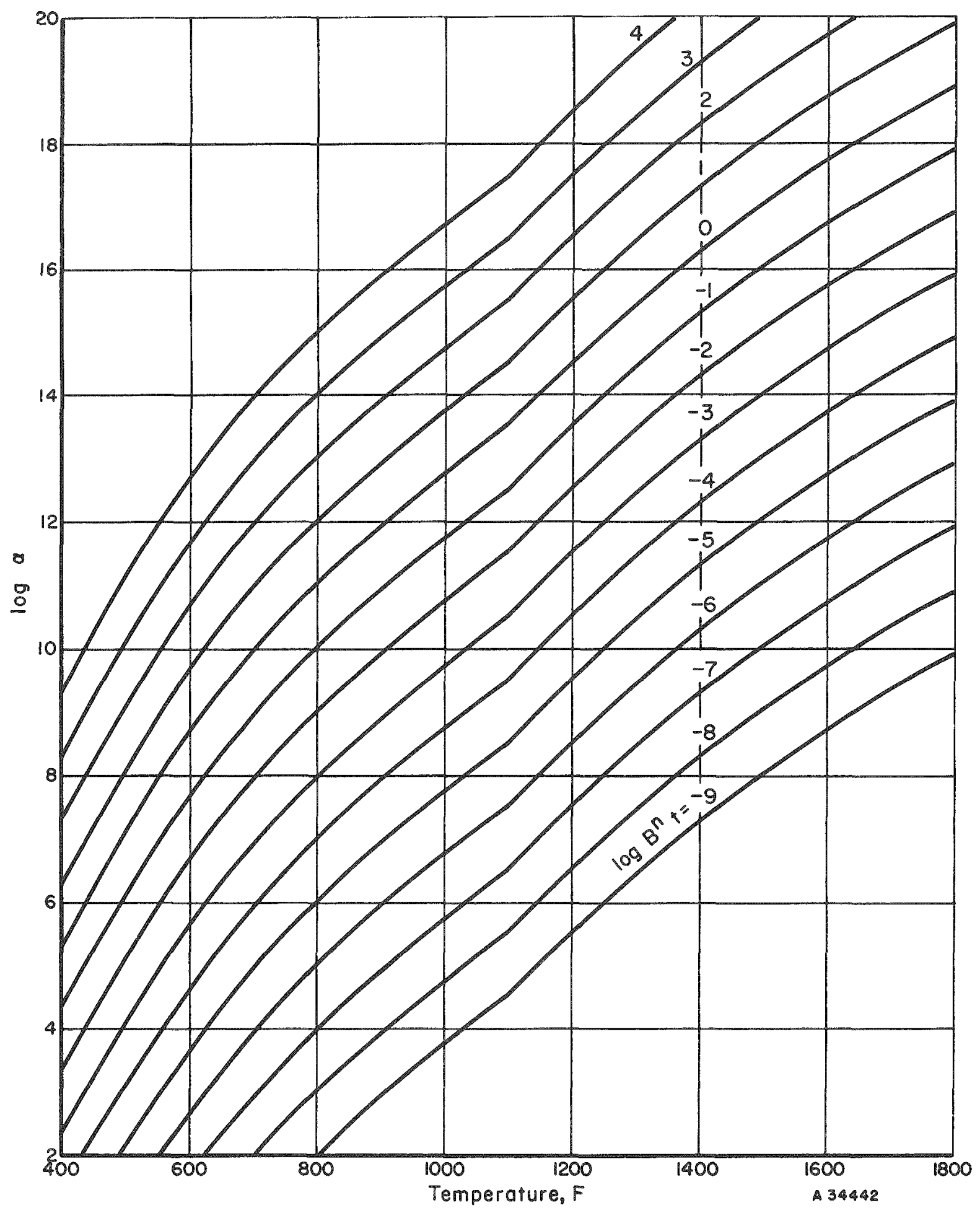

FIGURE 2. PLOT OF $\alpha$ VERSUS TEMPERATURE FOR VARIOUS CONSTANT VALUES OF $B^{n_{t}}$ 


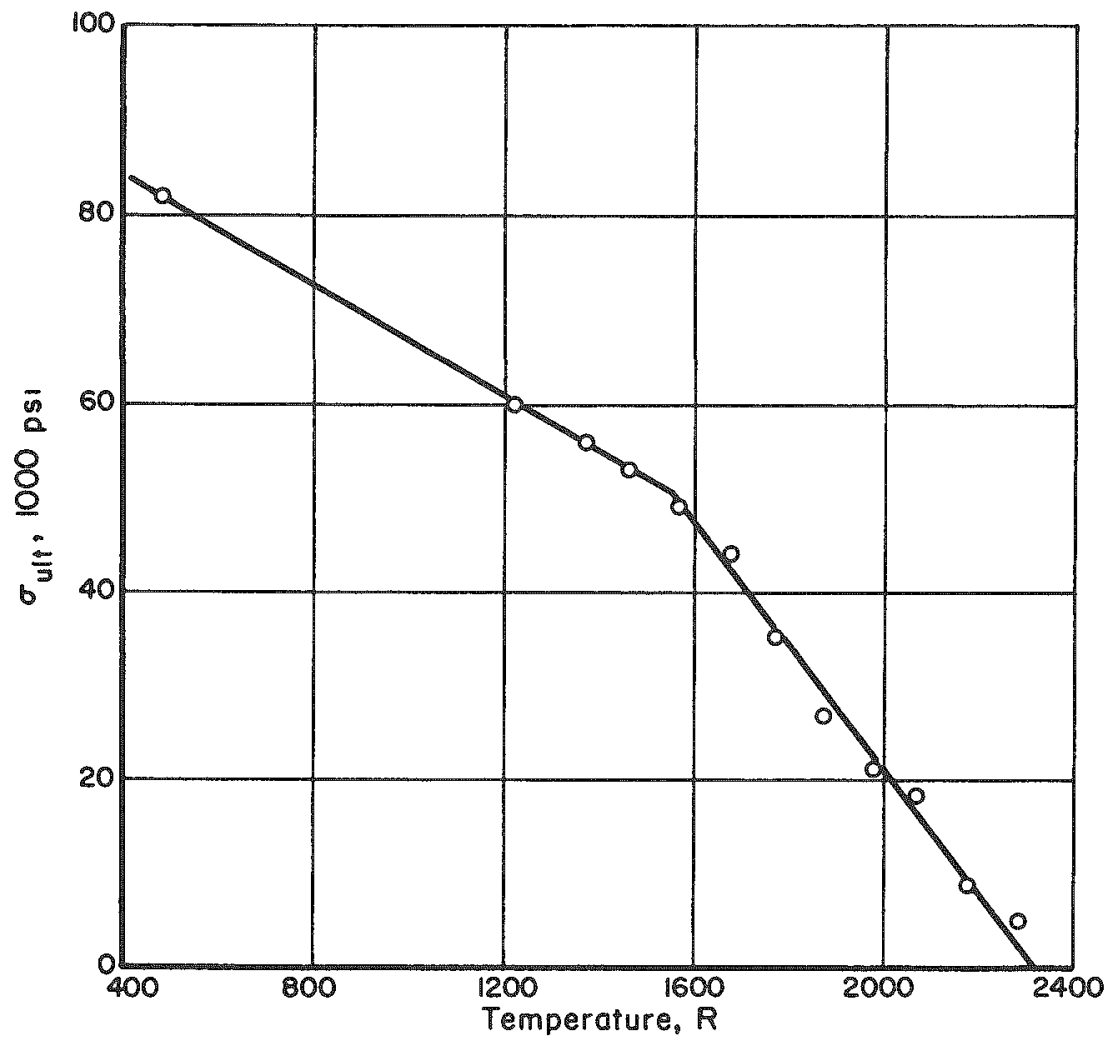

FIGURE 3. TENSILE STRENGTH OF 18-8 STAINLESS STEEL VERSUS TEMPERATURE

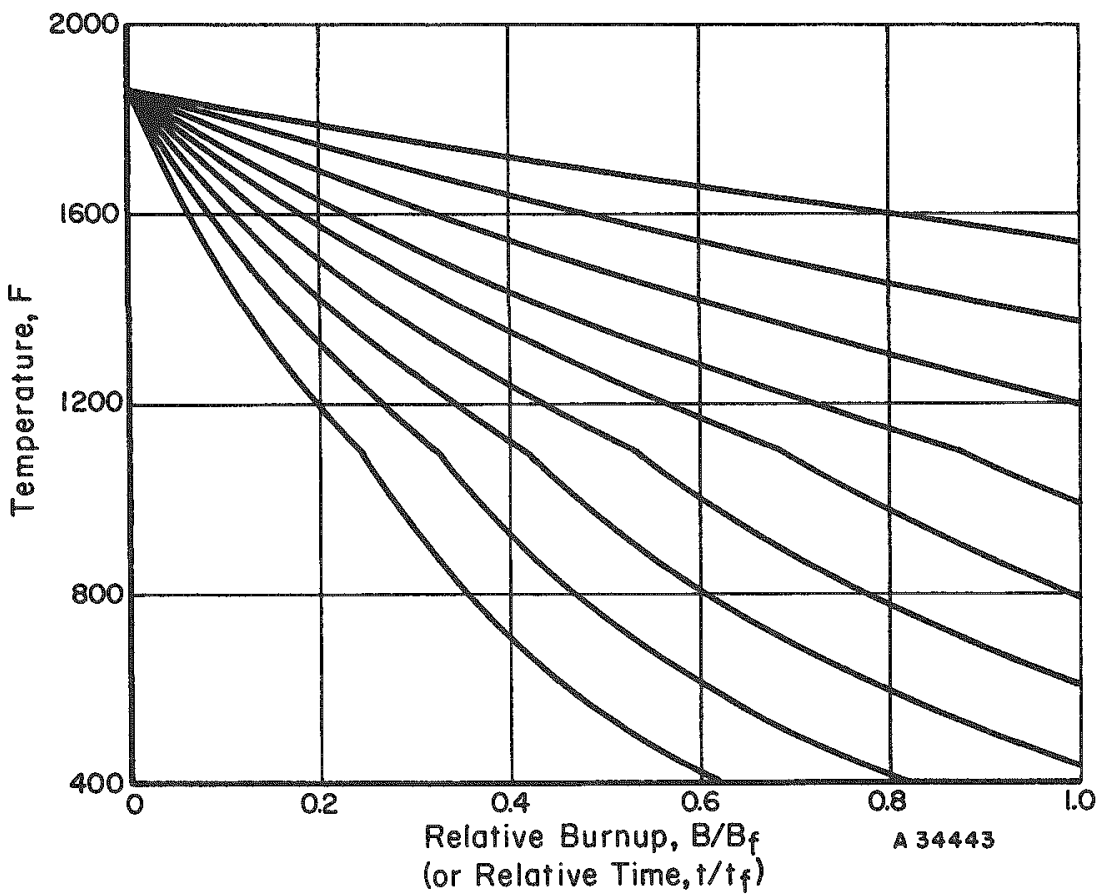

FIGURE 4. CONSTANT RELATIVE STRESS CURVES FOR VARYING TEMPERAT URES AND BURNUPS (OR TIMES) 
where $t_{1}=t / t_{f}$ is the fraction of time elapsed in the experiment. Substituting this in Equation (12) gives

$$
\frac{\sigma r}{\mathrm{~KB}_{f}}=\frac{\theta \mathrm{u}_{1}}{\sigma_{u l t}} \text {. }
$$

Thus, Figure 4 may be interpreted as showing curves of constant $\sigma_{r} / K_{f}$ for a variation in $t_{1}$ and $\theta$, and the temperature-versus-time graph may be used to estimate the critical stress condition.

It is emphasized that Figure 4 may not be used to determine whether a specimen has failed by a yield mechanism, but only to show the most probable time of failure if it is suspected that the failuxe was by short-term yield because of very short duration of high imposed stresses, as in a short temperature surge.

\section{Presentation and Analysis of the Experimental Results}

The methods outlined above were applied to experiments made on two sets of specimens irradiated in the MTR (6). The two sets differed only in their composition. The method of fabrication was the same in each case.

The cermets were made by blending the powdered components of the stainless steel and then mixing the result with either 25 or $30 \mathrm{w} / 0$ of $\mathrm{UO}_{2}$ powder. The mixtures were cold pressed, sintered, assembled into stainless steel jackets, and rolled to give specimens 1.5 by 0.75 by 0.045 in.

The specimens were irradiated in the Materials Testing Reactor at Arco, Idaho, In addition, two specimens of each type were irradiated in the Battelle Research Reactor.

A typical temperature history obtained for one of the specimens is shown in Figure 5. The temperature variability of this experiment can be clearly seen. It also can be clearly seen by comparing Figures 4 and 5 that the most critical stress state was reached at the end of the experiment. If the material had failed by short-term yield, the most probable failure time was at or near the end of the experiment. The temperature histories of the other specimens were also examined from the point of view of short-term yield. In no test was there any time at which there was a stress state severely more critical than the stress at the end of the test.

Using the temperature histories for each irradiated specimen, the numerical integration of Equation (9) was performed to obtain the creep parameter $\alpha_{0}$. The effective temperatures for each case were then read from Figure 2. The effective temperature and the time-averaged temperatures obtained from the temperature history shown in Figure 5 were also plotted in Figure 5. It is clear that the method of obtaining the effective temperature weights the temperatures near the end of an experiment more heavily than temperatures near the start of the experiment.

Table 1 gives the results of the experiments for 14 specimens and the values of average temperature and $\log \alpha$ computed for each.

Figure 6 was plotted from Table 1 and shows the correlation between $\log \alpha$ and per cent density loss for the $25 \mathrm{w} / 0 \mathrm{UO}_{2}$ specimens. This correlation shows that other 


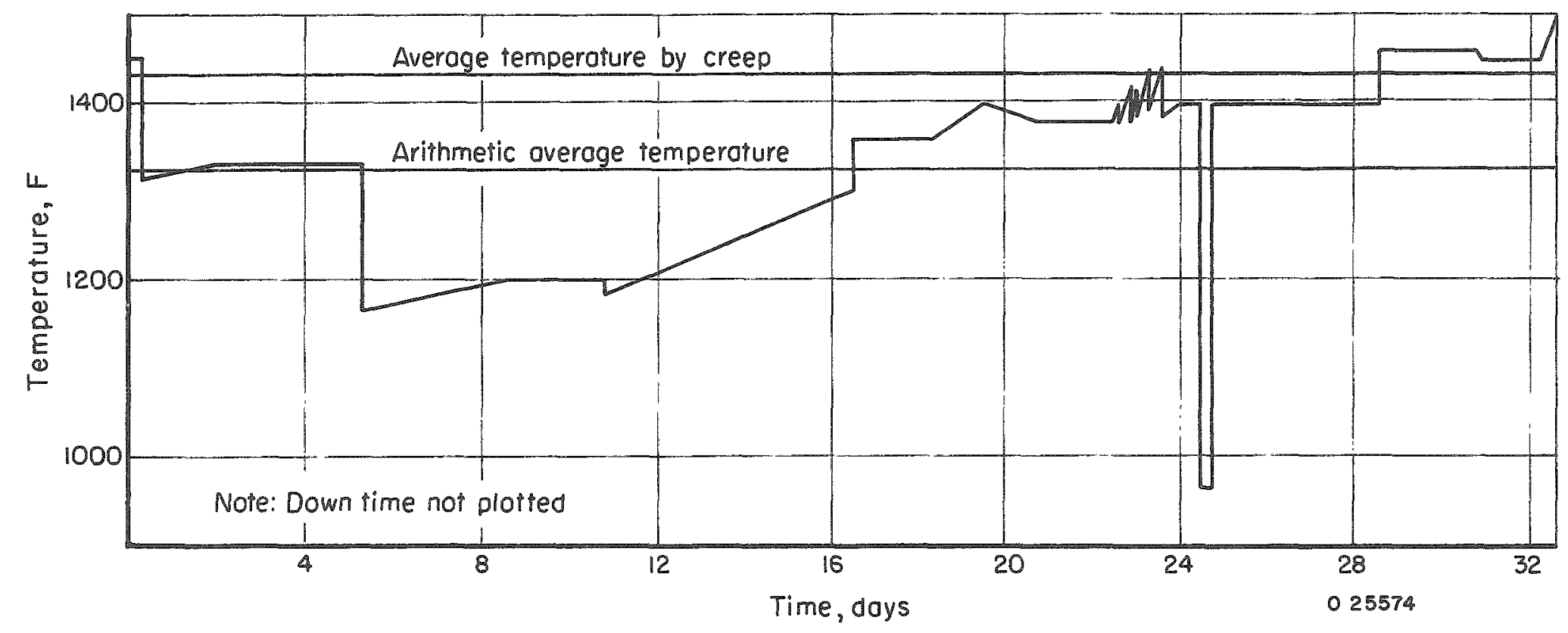

FIGURE 5. TEMPERAT URE HISTORY OF AN IRRADIATION EXPERIMENT SHOWING COMPARATIVE VALUES OF TWO AVERAGE TEMPERATURES 
TABLE 1. RESULTS OF IRRADIATION EXPERIMENTS AND APPLICATION OF ANALYSIS FOR TWO TYPES OF STAINLESS STEEL CERMETS

\begin{tabular}{|c|c|c|c|c|c|c|c|c|}
\hline Sample & $\begin{array}{l}\mathrm{UO}_{2} \\
\mathrm{w} / \mathrm{O}\end{array}$ & $\begin{array}{l}\text { Reactor } \\
\text { Used }\end{array}$ & $\begin{array}{l}\text { Exposure } \\
\text { Time, } \\
\text { days }\end{array}$ & $\begin{array}{l}\text { Uranium } \\
\text { Burnup, } \\
\text { per } \\
\text { cent }\end{array}$ & $\begin{array}{c}\text { Density } \\
\text { Loss, } \\
\text { pex } \\
\text { cent }\end{array}$ & $\begin{array}{l}\text { Sample } \\
\text { Condition }\end{array}$ & $\begin{array}{c}\text { Calculated } \\
\text { Average } \\
\text { Temperature, } \\
\text { F }\end{array}$ & $\log \alpha$ \\
\hline 23 & 25 & MTR & 32.7 & 5.4 & 1.04 & Good & 1725 & 13.9 \\
\hline 33 & 25 & MTR & 47.5 & 12.7 & 0.86 & Good & 1430 & 14.4 \\
\hline 35 & 25 & MTR & 47.5 & 16.6 & 1.72 & Good & 1550 & 15.7 \\
\hline 39 & 25 & MTR & 85.2 & 20.4 & 3.70 & $\begin{array}{l}\text { Large } \\
\text { blister }\end{array}$ & 1400 & 15.6 \\
\hline 40 & 25 & MTR & 85.2 & 20.7 & 3.45 & $\begin{array}{l}\text { Small } \\
\text { blister }\end{array}$ & 1417 & 15.7 \\
\hline 42 & 25 & BRR & 52.7 & 2.2 & 0.00 & Good & 1650 & 12.4 \\
\hline 43 & 25 & BRR & 52.7 & 2.6 & 0.00 & Good & 1650 & 12.7 \\
\hline 21 & 30 & MTR & 32.7 & 4.9 & 1.15 & $\begin{array}{l}\text { Small } \\
\text { blister }\end{array}$ & 1655 & 13.7 \\
\hline 31 & 30 & MTR & 47.5 & 17.5 & 2.09 & $\begin{array}{l}\text { Small } \\
\text { blister }\end{array}$ & 1533 & 15.7 \\
\hline 32 & 30 & MTR & 47.5 & 15.6 & 1.84 & Ruptured & 1395 & 14.3 \\
\hline 36 & 30 & MTR & 85.2 & 25.1 & $=$ & Ruplured & 1475 & 16.2 \\
\hline 37 & 30 & MTR & 85.2 & 22.2 & 5.17 & Ruptured & 1300 & 14.5 \\
\hline 44 & 30 & BRR & 52.7 & 2.4 & 0.00 & Good & 1650 & 12.6 \\
\hline 45 & 30 & BRR & 52.7 & 2.8 & 0.00 & Good & 1650 & 12.9 \\
\hline
\end{tabular}




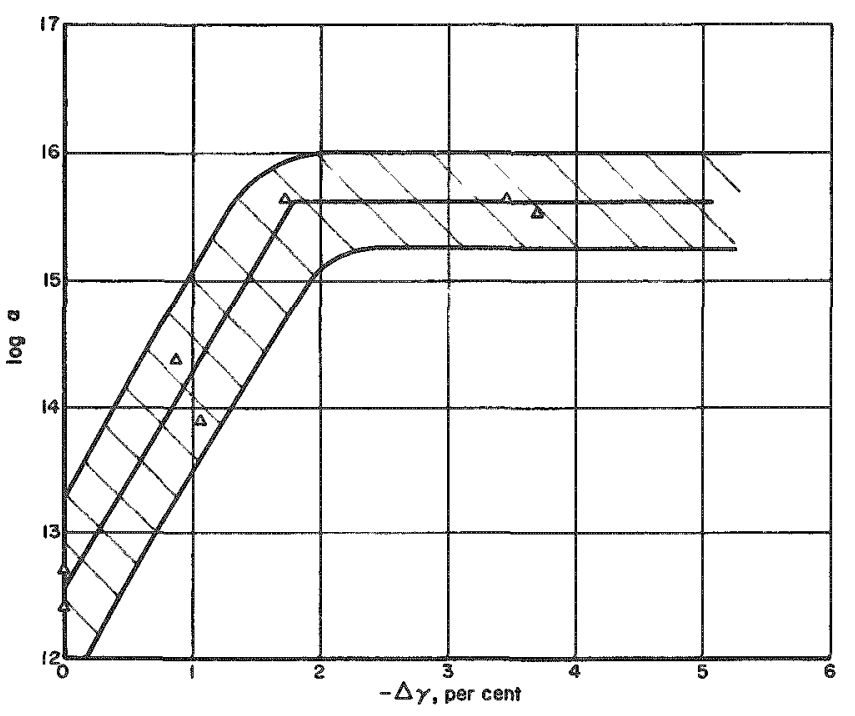

FIGURE 6. CORRELATION OF LOG $\alpha$ WITH PERCENTAGE DENSITY LOSS, $-\Delta \gamma$ FOR $25 \mathrm{w} / \mathrm{OUO}_{2}$ SPECIMENS

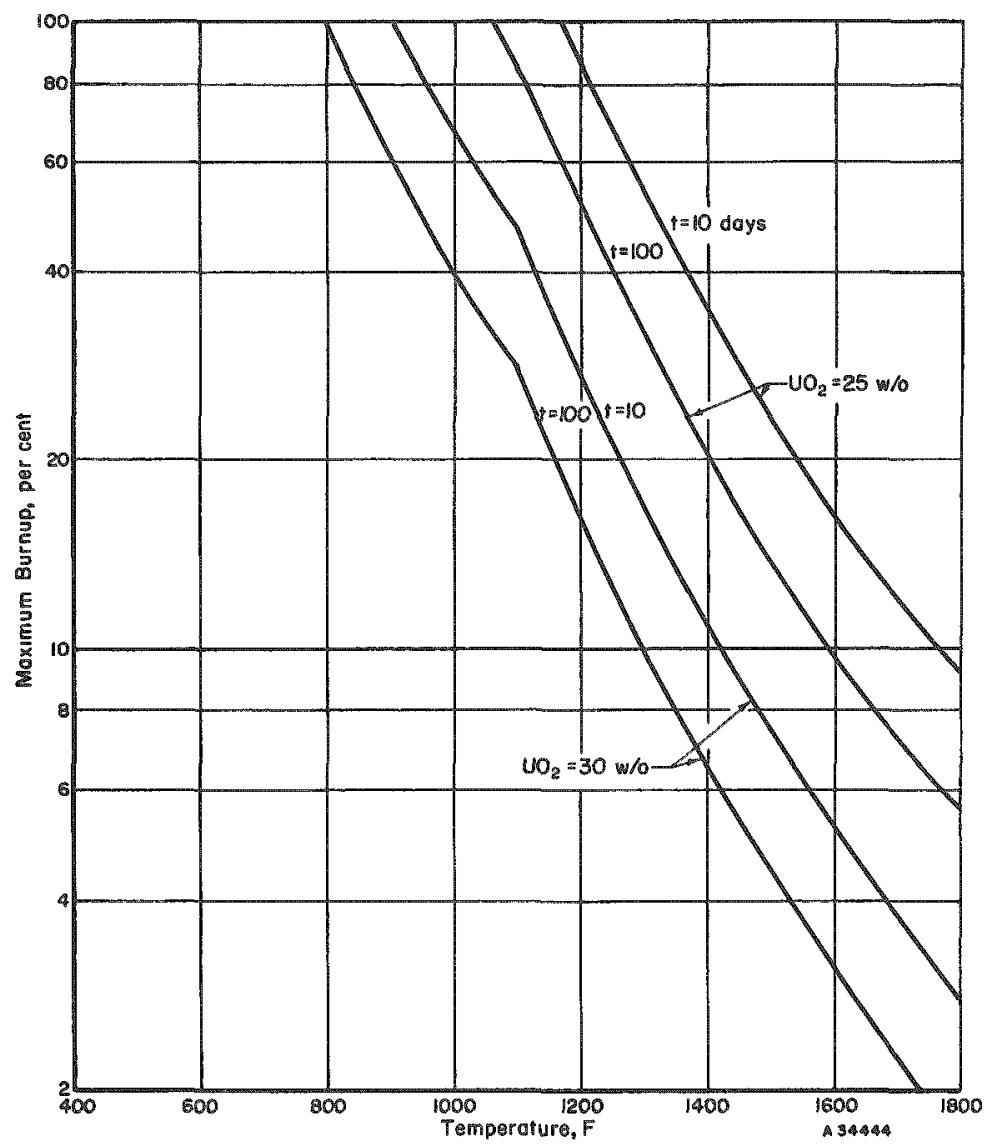

FIGURE 7. CORRELATION OF PERMISSIBLE BURNUPS WITH SPECIMEN TEMPERATURES FOR TWO SPECIMEN TYPES AND FOR TEST DURATIONS OF 10 AND 100 DAYS 
specimens of the same construction would probably fail at a value of $\log \alpha$ between 15.25 and 16.0. The failure point is seen as that point for which the value of the density loss becomes large for little or no further increase in the value of $\log \alpha$.

The data for the $30 \mathrm{w} / 0 \mathrm{UO}_{2}$ specimens were not plotted, since all but two of the specimens had failed and since the deformations of a set of failed specimens could not be expected to correlate with $\log \alpha$. However, the data indicate that the $30 \mathrm{w} / 0 \mathrm{UO}_{2}$ specimens could be expected to fail at values of $\log \alpha$ between 13 and 13. 7 .

It is obvious that the obtained values of $\log \alpha$ at failure are very uncertain because of the small numbers of specimens tested for each type. However, the results indicate that, with a sufficient number of experiments, the above procedures could be used to determine accurately the failure conditions for a given set of specimens.

Suppose now that the values of $\log \alpha$ of 15.25 and 13 were found to be the upper safe limits for the ir radiation of the $25 \mathrm{w} / \mathrm{o}$ and $30 \mathrm{w} / 0 \mathrm{UO}_{2}$ specimens. On this assumption, curves were constructed in Figure 7 to show the permissible burnups as functions of test temperature for two different test durations. This graph illustrates the interrelations between the test conditions that could be used for reactor design if the failure conditions were determined more accurately.

The results of the analysis of the two sets of data clearly illustrate the way that $L$, the limit value of $\log \alpha$, could be used to correlate the effects of changes in specimen structure. Here the change in amount of $\mathrm{UO}_{2}$ from $25 \mathrm{w} / 0$ to $30 \mathrm{w} / \mathrm{o}$ caused a decrease in $L$ from around 15 to 13 . Tests of similar specimens containing other fractions of $\mathrm{UO}_{2}$ could be made to demonstrate the effects of varying the composition of this type of cermet. The advantages of using a single parameter such as $\mathrm{L}$ for this correlation are obvious. Once $L$ is found as a function of composition, graphs similar to Figure 7 could then be constructed to determine the optimum reactor design.

\section{CONCLUSIONS}

Methods have been presented in this report for the comparison of the severity of the conditions of irradiation of dispersion fuel elements for two types of failure mechanisms. The assumptions that were made led to very simple models which are nevertheless believed to be reasonable and a significant advance over theories previously available for solution of the problem considered. These models were checked against the experimental results for two sets of specimens. Although no positive verification of the short-term stress model was obtained, the creep model yielded approximate failure limits for both specimen types. However, the models are to be regarded as only the first step in creating a complete model of the irradiation effects on dispersion fuels. It is expected that much experimentation will be needed to establish quantitative measures of the structural effects. The models presented herein should facilitate the interpretation of such experiments. The application of the models has been explained in detail to aid and encourage other investigators in evaluating the applicability of this method of correlating irradiation data. 


\section{REFERENCES}

(1) Beaner, R. J., Waugh, R. C., and Leitten, C. F., "Specifications for Army Package Power Reactor (APPR-1) Fuel and Control Rod Components", ORNL-2225 (August 7, 1957).

(2) "The Army Reactor Program APPR-1 Operation Experience", Nucleonics, $17(2), 50-51(1959)$.

(3) Weber, C. E., and Hirsch, H. H., "Dispersion Type Fuel Elements", Progress in Nuclear Energy, Vol 5, McGraw Hill, New York (1956), pp 523-534.

(4) Digest of Steels for High-Temperature Service, The Timken Roller Bearing Company, Fifth Edition (1940).

(5) Sherby, O. D., and Dorn, J. E., "Some Observations on Correlation Between the Creep Behavior and the Resulting Structures in Alpha Solid Solutions", Trans. AIME, 197, 324-330 (1953).

(6) Saling, J. H., BMI, Private Communication.

DLK/LEH/BWD:jch 